\title{
AVANCES DE LA NEUROCIENCIA Y SUS IMPLICACIONES PARA LA CIENCIA DE LA INFORMACIÓN
}

\author{
Neuroscience advances and their implications \\ for Information Science
}

Paul Sturges

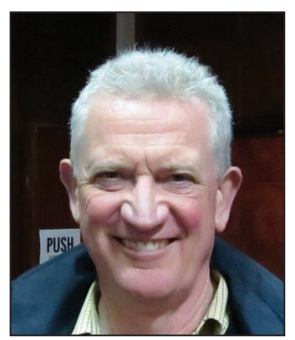

Paul Sturges es profesor emérito en el Department of Information Science de la Loughborough University. Tiene 40 años de experiencia como investigador, escritor (más de 150 publicaciones) y orador (en más de 60 países) en una amplia gama de temas de ciencias de la información, con énfasis particular en los países en desarrollo y, más recientemente, en aspectos de libertad intelectual. Su interés por la neurociencia surge del interés en localizar la libertad intelectual en las facetas básicas de la función del cerebro humano. En el período 2003-2009 fue presidente del comité Freedom of Access to Information and Freedom of Expression (Faife) de la International Federation of Library Associations and Institutions (IFLA). En 2010 recibió la Order of the British Empire (OBE) y en 2011 la medalla de la IFLA. http://orcid.org/0000-0001-6970-6739

Loughborough University, Department of Information Science Loughborough LE11 3TU, Reino Unido

\begin{abstract}
Resumen
Algunos elementos que aparecen en libros publicados recientemente sobre neurociencia permiten sugerir un fortalecimiento de la teoría de la ciencia de la información. Tradicionalmente la teoría de la información ha descuidado la dimensión humana a favor de enfoques "científicos" derivados a menudo del modelo Shannon-Weaver. Sin embargo ahora los neurocientíficos discuten acaloradamente sobre evidencias halladas a partir de estudios de casos, experimentación no intrusiva, y medidas obtenidas con tecnologías como electroencefalogramas, tomografía por emisión de positrones (PET), resonancia magnética funcional (FMR) y magnetoencefalografía (MEG). En este artículo se explora cómo se pueden cruzar los descubrimientos de la neurociencia con ideas como el pensamiento rápido y lento de Kahneman, y el flujo de Csikszentmihalyi, todo ello conectado con la ciencia de la información. Se argumenta que se pueden extraer los comienzos de una base teórica para la búsqueda de información en la web actual, contrapuesta a los métodos de recuperación de información establecidos. Se sugiere que programas de investigación con colaboración entre neurocientíficos y científicos de la información podrían ser muy reveladores.
\end{abstract}

\section{Palabras clave}

Neurociencia; Cerebro humano; Procesos mentales; Pensamiento; Proceso de información; Conciencia; Subconsciente; Ciencias de la información.

\begin{abstract}
Insights from the recent wealth of popular books on neuroscience are offered to suggest a strengthening of theory in information science. Information theory has traditionally neglected the human dimension in favour of 'scientific' approaches often derived from the Shannon-Weaver model. Neuroscientists argue in excitingly fresh ways from the evidence of case studies, non-intrusive experimentation and the measurements that can be obtained from technologies that include electroencephalography, positron emission tomography (PET), functional magnetic resonance imaging (fMRI), and magnetoencephalography (MEG). The way in which the findings of neuroscience intersect with ideas such as those of Kahneman on fast and slow thinking and Csikszentmihalyi on flow, is tentatively explored as lines of connection with information science. It is argued that the beginnings of a theoretical underpinning for current web-based information searching, as opposed to established information retrieval methods, can be drawn from this. It is proposed that collaborative research programmes between neuroscientists and information scientists could be extremely revealing.
\end{abstract}

\section{Keywords}

Neuroscience; Human brain; Mental processes; Thought; Information processing; consciousness; Subconscious; Information science. 
Sturges, Paul (2015). "Avances de la neurociencia y sus implicaciones para la ciencia de la información”. El profesional de la información, v. 24, n. 2, marzo-abril, pp. 168-175.

http://dx.doi.org/10.3145/epi.2015.mar.10

\section{Introducción}

Las ciencias de la información son un campo de trabajo estimulante por muchas razones. Paradójicamente una de ellas es porque carece de lo que se considera como la piedra de toque de la fortaleza de una disciplina: un cuerpo teórico potente y distintivo. Debido a que las teorías de la información existentes no siempre nos inspiran o implican, nos vemos obligados a mirar hacia el exterior para encontrar ideas, métodos de investigación y áreas de estudio. Podría preocuparnos la falta de teorías y de hipótesis para la investigación, pero al investigador imaginativo se le ofrece un maravilloso panorama donde elegir en la actividad humana y en diversos ambientes de partida donde se puede percibir la información en acción. En ciencias de la información queda mucho trabajo por hacer de abrir caminos, tanto a nivel micro (estudios empíricos sobre problemas específicos en ambientes bien definidos) como a nivel teórico o macro. Para contribuir a fundamentar la ciencia de la información todavía debemos mirar hacia fuera.

El argumento en el que se basa este artículo es que en el campo de la neurociencia podemos descubrir elementos útiles que necesitamos para crear una disciplina más rica y significativa. Lo que sigue se basa principalmente en lecturas de neurociencia popular realizadas por un científico de la información. La ruta de estudio hacia una nueva disciplina resulta más fácil si la misma tiene un cuerpo de escritura popular o divulgativo, algo que sucede con la neurociencia. Se han publicado una gran cantidad de libros, artículos de prensa y programas de radio y televisión que ayudan a popularizar los hallazgos de la neurociencia. Algunos de los libros recientes se citarán específicamente en el texto que sigue, pero también se han consultado otros como los de Goldblum, 2001; Winston, 2003; Zimmer, 2005; Edelman, 2006; Gay, 2009; Hood, 2009; Appleyard, 2011; Churchland, 2013; y Kaku, 2014. Los artículos en revistas y periódicos, muchos de ellos en forma de reseñas de libros, son demasiado numerosos para mencionarlos aquí.

Ante un grado de popularización como éste siempre existe el peligro de que la disciplina en cuestión sea tergiversada en interés del sensacionalismo. En mi caso las lecturas las realicé teniendo en cuenta que la neurociencia es particularmente vulnerable a ello. No ignoramos la opinión que a menudo se escucha, de que la neurociencia popular, tal vez incluso la propia neurociencia, exagera la capacidad de la investigación actual para explicar los fenómenos que trata. Existe la sensación de que está en un proceso de cambio de paradigma, pero es natural que se produzca alguna aseveración poco creíble sobre tal cambio. Tallis (2011) y Satel y Lilienfeld (2013) son críticos convincentes. En particular, Tallis, p. 60, sugiere que "un nuevo paradigma significa un montón de bonitas conferencias y ponencias". Sin embargo, añade que: "también puede ayudar a superar una crisis de confianza en el valor o en la validez de lo que se está haciendo". Sin duda ésta es la cuestión: una excursión al área de la teoría básica puede valer la pena, pero requiere "bonitas conferencias y ponencias". Respetando esas impaciencias por hacer avanzar la disciplina, el punto de partida de este trabajo es que la bibliografía sobre neurociencia ofrece ahora un conocimiento del cerebro y su funcionamiento que desafía las suposiciones previas de varias disciplinas centradas en lo humano. Estudios como la teología, psicología, pedagogía, informática y, por supuesto, las ciencias de la información, están obligadas a responder a los hallazgos de la neurociencia y en general a reconocer que sus suposiciones acerca de los seres humanos se han basado en percepciones nebulosas, arraigadas en investigaciones insuficientes.

En la mayor parte de estudios sobre teoría de la información y, en particular, sobre teoría de la búsqueda de información, no se ha dado suficiente importancia al papel del cerebro humano

\section{Cambiar las ciencias de la información}

Una aproximación a la ciencia de la información centrada en el cerebro requiere un reexamen y un replanteamiento serio de gran parte de lo que se ha escrito o enseñado en esta materia durante más de medio siglo. Nuestra opinión es que, en la mayor parte de la gran cantidad de escritos sobre la teoría de la información y, en particular, sobre la teoría de la búsqueda de información, no se ha dado suficiente importancia al papel del cerebro humano. Sin embargo, el cerebro es el órgano donde las percepciones incoherentes se convierten realmente en información, y adquieren la importancia que pueden contener. Las ciencias de la información están en su mínima utilidad cuando tienen una visión simplista de la mente y hacen uso del modelo de Shannon-Weaver que en ciencias de la comunicación trata del problema de la transferencia de señales a través de un canal "ruidoso" (Shannon; Weaver, 1949). Pero como Rose (2005, p. 103) escribe:

"Afecto y cognición están inextricablemente involucrados en todos los procesos del cerebro y de la mente, creando significado a partir de la información, una razón más que demuestra que el cerebro no es un ordenador".

Varios estudios sobre búsqueda de información, como los de Wilson (2000), demuestran que ésta se ha ido refinando y adaptando a lo largo de los años. La psicología cognitiva ha avanzado mucho más sobre la respuesta humana a la información. Sin embargo, sigue existiendo la sensación de que la mente puede compararse a un ordenador, y que gran parte de lo que hay que decir puede ser considerado como de una máquina parlante a otra máquina, con la máxima eficacia. 


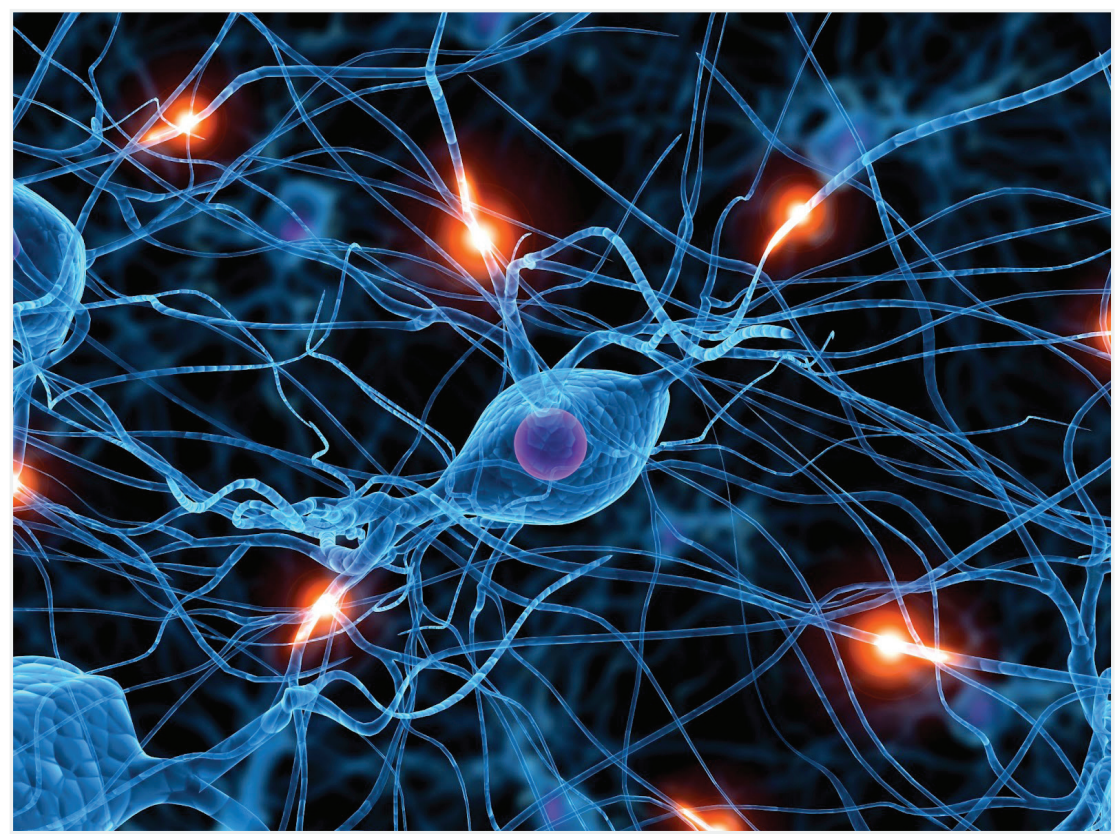

Sinapsis y redes neuronales

Fuente: https://estrellasur.wordpress.com

Si nos fijamos en los mejores títulos recientes sobre información vemos que la tendencia persiste. Gleick (2011) ofrece una fascinante y estimulante lectura, llena de historias y ejemplos, pero en esencia no se aleja mucho de la perspectiva de Shannon-Weaver. En los elegantes y convincentes pensamientos sobre la información de Floridi (2010) todavía se puede leer cómo se trata la información como si fuera un fenómeno independiente del observador o receptor. Así, habla de categorías como información matemática, información semántica o información biológica. Y en un capítulo sobre la información neural añade:

"El cerebro sigue siendo un continente en gran parte inexplorado. Uno de los grandes enigmas de la información es saber cómo señales físicas, transducidas por el sistema nervioso, dan lugar a información semántica de alto nivel" (p. 86).

Esto es sin duda cierto, pero ese enigma se encuentra justo en el centro de cualquier teoría de la información y tenemos que hacerle frente, por muy problemático que sea.

En la mayor parte de tratados sobre la teoría de la búsqueda de información, la "mente" de un "yo" articulado de manera imperfecta solicita y recibe información de forma estructurada. Sin embargo, si lo reflexionamos, estas formas se parecen poco a las corazonadas y las inspiraciones que tenemos en la práctica con la información, o sus confusiones y componendas. Un buscador de información intuitivo actúa de una manera consciente a partir de la primera percepción de una necesidad de información imprecisa, definiendo y refinando la necesidad, y transformándola en términos de búsqueda que se pueden utilizar en los recursos de información y obteniendo una respuesta adecuada. Se reconozca o no, esto se parece a un enfoque inspirado en ShannonWeaver. En defensa de la ciencia de la información hay que decir que la neurociencia hasta hace poco ha ofrecido sólo una ayuda limitada a la fundamentación de su teoría. El conocimiento del cerebro ha sido frustrantemente incompleto y no especialmente útil para el común de los mortales. Esto ha cambiado. Si preguntamos por qué se ha producido un cambio, la respuesta es claramente porque ha mejorado la tecnología disponible para su investigación.

\section{Neurociencia}

En el pasado existía solamente una gama limitada de enfoques para tratar de entender el cerebro. Una maravillosa exposición en la Wellcome CoIlection en Londres en mayo de 2012 (Kwint; Wingate, 2012) ilustró gráficamente esto de forma impactante, a veces extraña, y a menudo inspiradora. Hoy en día la ética médica descarta la investigación y la experimentación intrusivas con los cerebros de personas vivas. La disección de los cerebros de muertos permitió establecer la forma y la estructura básica del cerebro ya en los tiempos helénicos. Se dio nombre a las distintas partes y poco a poco se fue desarrollando una idea relativamente clara de las funciones que realizan.

Una versión elemental podría ser: el cerebro tiene dos hemisferios, cada uno dividido en cuatro partes: lóbulo occipital (relacionado con el proceso visual); lóbulos temporales (proceso del lenguaje y del sonido); lóbulos parietales (percepciones del espacio); lóbulos frontales (pensamiento y planificación). La distinción entre los dos hemisferios es importante y volveremos a ello en la siguiente sección. Debajo de los hemisferios se encuentran las estructuras del sistema límbico que se consideran el asiento de las emociones, y el hipocampo, que desempeña un papel en el almacenamiento y la recuperación de los recuerdos. Luego está el cerebelo, en la parte posterior del cerebro, que se ve cada vez más como la sede de diversos aspectos de la cognición, incluyendo el lenguaje y la lectura.

Una lectura más extensa sobre todo esto revela que los neurocientíficos han avanzado mucho en la identificación de las funciones que éstas y otras partes del cerebro parecen realizar y cómo interactúan entre sí. Sin embargo, ha fallado el intento de ligar funciones específicas del cerebro exclusivamente a unas determinadas áreas del mismo. Lo que sucede en el cerebro es mucho más complejo.

Alguna noción sobre esa complejidad se desarrolló en el siglo XIX, cuando por inferencia se supo mucho a partir de la experiencia de personas que habían sufrido lesiones cerebrales y neurológicas. Al principio, de las respuestas de la gente que padecía una lesión cerebral se pudieron inferir las funciones que dependen de las zonas dañadas, pero más tarde se hizo evidente que el cerebro tiene un grado de plasticidad, que a menudo le permite compensar los daños. Uno de los primeros casos ampliamente estudiados y difundidos de daño cerebral que dio indicios sobre esto fue el de Phineas Gage. En 1848, cuando trabajaba como ingeniero en proyectos ferroviarios, una explosión le clavó una barra de hierro entre los lóbulos frontales. Esto no lo mató ni dañó muchas de sus fun- 
ciones mentales, pero parece que afectó a su personalidad, que se transformó de dócil y eficiente en irritable y errática. El caso de Gage alentó a teorizar sobre la función de los lóbulos frontales y, presumiblemente, también al uso médico de la lobotomía para tratar trastornos de la personalidad. Posteriormente, los médicos y neurólogos han estudiado en detalle la forma en que se han producido cambios compensatorios después de daños en las áreas del cerebro (Ramachandran; Blakeslee, 1999 y Ramachandran, 2004).

Quizás la cuestión importante sea que el cerebro tiene una asombrosa capacidad para cambiar las funciones entre las áreas en respuesta a un daño, lo que sugiere que la comunicación y lo que podríamos llamar cooperación entre las áreas del cerebro es al menos tan importante como la especialización. También parece que el cerebro crece y se fortalece según cómo se utiliza. Una formulación clara de esto la ofrece Carr (2010):

"Los recientes descubrimientos sobre la neuroplasticidad hacen más visible la esencia del intelecto, y más fáciles de marcar sus pasos y fronteras. Nos dicen que las herramientas que el hombre ha utilizado para apoyar o ampliar su sistema nervioso -todas aquellas tecnologías que a través de la historia han influido en la forma de encontrar, almacenar e interpretar la información, la forma en que dirigimos nuestra atención y hacemos intervenir nuestros sentidos, cómo recordamos y cómo olvidamos- han dado forma a la estructura física y al funcionamiento de la mente humana. Su uso ha fortalecido algunos circuitos neuronales, dejando desvanecer otros" (p. 48).

A lo que Carr alude aquí es a que la ansiedad que provoca el uso de internet está cambiando los cerebros de los usuarios, y tal vez no para bien. En su sugerencia está el germen de todo un posible programa de investigación, y los científicos de la información, basándose en la neurociencia actual, estarían bastante bien preparados para realizarlo.

Lo que ha hecho posible el gran progreso de la investigación

Cuanto más aprendemos sobre el cere-

bro menos obvio parece ser que haya un lugar específico para la conciencia

en neurociencia es la disponibilidad de una variedad de sofisticadas técnicas de escaneo. En la primera mitad del siglo XX comenzaron a desarrollarse formas de medir el flujo sanguíneo y la carga eléctrica en el cerebro. Más tarde, la técnica conocida como tomografía por emisión de positrones (PET) proporcionó imágenes tridimensionales del cerebro mientras trabaja. Después, la resonancia magnética (MR) y la resonancia magnética funcional (FMR) han permitido obtener imágenes de mayor claridad. Ahora la magnetoencefalografía (MEG) puede leer rastros de actividad magnética muy pequeños durante períodos de milésimas de segundo. Hoy en día se puede monitorizar la actividad de una sola neurona, o de varias neuronas trabajando juntas.

“Con escaners PET y fMR ahora podemos encontrar qué partes del cerebro están activas o inactivas cuando el paciente realiza una acción concreta o se involucra en un proceso mental específico" (Ramachandran, 2004, p.85).

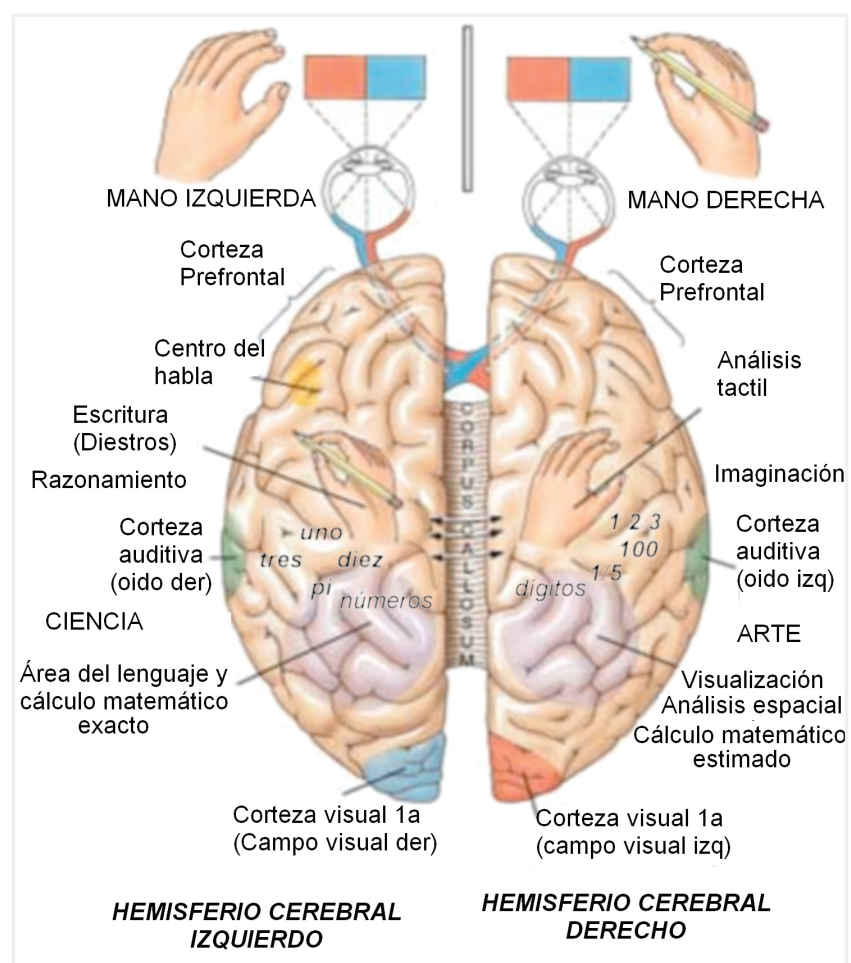

Áreas cerebrales

Fuente: https://rv2010.files.wordpress.com

Está en proceso de reducirse la vaguedad que antes se tenía sobre lo que sucede realmente en el cerebro.

Una de las consecuencias más importantes de esto es que cuanto más aprendemos sobre el cerebro menos obvio parece ser que haya un lugar específico para la conciencia. EI desafío de la localización de la conciencia ha sido descrito así:

"saber cómo las razones intencionales pueden conciliarse con causas neuronales a través de un mapeo de muchos-a-uno de la actividad neuronal en la cognición" (Scholl, en: Gay, 2009, p. 177).

Ha sido el detallado conocimiento de la neuroplasticidad del cerebro lo que ha llevado a la conclusión de que no es necesariamente un área específica del cerebro lo que tenemos que buscar para comprender aspectos de la función cerebral, sino a las conexiones neuronales entre las partes. A la suma de todas estas conexiones a menudo se la denomina ahora conectoma (Seung, 2012) y se usa una especie de mantra: "Tú eres tu conectoma", o como dice Le Doux (2002, p. ix): "Tú eres tus sinapsis". Esto nos acerca a conocimientos acerca de la conciencia humana útiles para las ciencias de la información y para otras disciplinas.

En concreto, existe una nueva comprensión de la importancia de la conciencia en relación con la gran cantidad de funciones automáticas que realiza el cerebro. Esto se relaciona con una línea de investigación que se ha seguido intensamente desde que Freud señaló hace más de cien años que al menos la mitad de lo que sucede en el cerebro se lleva a cabo a un nivel subconsciente o inconsciente. Probablemente la perspectiva freudiana se concentra demasiado exclusivamente en los problemas y trastornos que la mente 


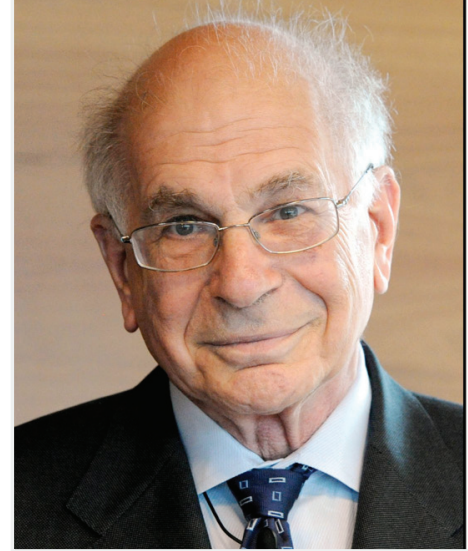

Fuente: $h t t p: / / c d n . t h e d a i l y b e a s t . c o m$

inconsciente provoca a nuestro yo consciente. A su vez esto podría haber distraído nuestra atención del papel positivo desempeñado por el sistema nervioso autónomo, que puede por ejemplo identificar cosas como patrones estadísticos antes que la conciencia. De hecho, como escribe Eagleman (2011, pp. 131-2): “Casi todas nuestras acciones están dirigidas por subrutinas alienígenas, también conocidas como sistemas de zombies". Los sistemas de aprendizaje y las acciones instintivas generalmente funcionan con esa clase de subrutinas. La conciencia se necesita cuando hay un nuevo problema a resolver: ofrece la flexibilidad cognitiva que los sistemas de zombies no pueden ofrecer. Eagleman concluye que la conciencia es útil, pero sólo en pequeñas cantidades y para tareas específicas (como, por ejemplo, la planificación a largo plazo).

En esta visión de las cosas, el cerebro inconsciente sirve a la conciencia solamente cuando hay una necesidad de conocer, ignorando las cosas hasta que es necesario el pensamiento sistemático, y seguidamente proporciona la información de forma muy elaborada para que nos sea posible contemplar la situación y tomar decisiones. Nosotros mismos no somos conscientes de la gran mayoría de las actividades de nuestro propio cerebro y tampoco podríamos tenerlas en cuenta si supiéramos lo que está pasando. El hecho de que esto parezca reducir la humanidad a un conjunto de respuestas subconscientes automáticas, algunas de ellas descritas con la fea palabra "zombi", perturba particularmente a aquellos que sienten que se requiere una interpretación (potencialmente) menos reductora. Por ejemplo, Hick (2006, p. 205) señala:

“No sólo todas las relaciones personales, sino todo el trabajo creativo en literatura, pintura, música, arquitectura, e igualmente todos los grandes avances científicos, presuponen un grado significativo de libertad intelectual y física".

Bueno, sí, pero ¿qué significa "un grado significativo" en este contexto?

Como ya hemos sugerido, tal vez el enfoque más robusto, pero también decepcionante por lo corto, a la respuesta a esta pregunta es el de Tallis (2011) que se refiere a la mente humana como mucho más que la suma de la actividad neuronal que actualmente somos capaces de medir. Él lla- ma la atención sobre "un vacío, que no puede ser ignorado entre la experiencia y lo que observa la neurociencia" (p. 97), expresando su escepticismo sobre "las pretendidas correlaciones entre las funciones psicológicas y la actividad cerebral basadas en técnicas de neuroimagen" (p. 193). Dice que algunos de los problemas se remontan a la utilización del modelo de Shannon-Weaver, argumentando que deshumaniza a la percepción, la atención y la conciencia de los seres humanos en favor de un énfasis en una definición de información neutral, sin relación con el significado o importancia. De hecho, Tallis a menudo conduce al lector a esperar que va a encontrar un lugar para algo como un alma inmortal que contribuye a los logros humanos. Como humanista ateo, según se autoproclama, Tallis rechaza esto, pero su falta de voluntad para ser más específico acerca de lo que hace que los seres humanos no puedan medirse sólo por su actividad cerebral, es en última instancia insatisfactorio.

Después de leer a Tallis y tomando nota de sus objeciones, volvemos de nuevo a nuestro tema de la interacción entre el subconsciente y el consciente, sobre el que la neurociencia centra la atención. Reducido a un nivel más bien simplista, lo que obtenemos de las lecturas de la neurociencia es que somos tanto criaturas de instinto como individuos racionales. Ahora podemos ver en acción estos dos aspectos de nuestro ser en la observación científica del funcionamiento del cerebro. Si relacionamos entonces esta noción con la información, comienza a aparecer una nueva luz.

\section{Es como si hubiéramos estado esperan- do algo que pudiera responder a nues- tra capacidad inherente para trabajar en flujo. Hoy la espera ha terminado: tene- mos una respuesta en la Web}

La información es lo que es porque somos lo que somos, y somos cerebros en el centro de un aparato sensorial que nos alimenta de percepciones, con una individualidad condicionada por nuestra existencia social con otros seres humanos. Con el cerebro como consistente punto de partida para nuestra teorización, estamos ahora obligados a introducirnos en los temas que forman el área disciplinar de las ciencias de la información con nuevos puntos de vista. Lo que esas formas son exactamente y a dónde nos llevan actualmente sólo puede esbozarse como un conjunto de sugerencias, y la siguiente sección es simplemente una pequeña incursión en este campo.

\section{Implicaciones para la información}

La idea del cerebro como un órgano que recibe y procesa grandes cantidades de información en un sinfín de formas codificadas tanto profundamente como ligeramente, pero no necesariamente dominado por la intervención consciente, nos lleva naturalmente a preguntar: “¿Es ahí donde encontraremos implicaciones importantes para la búsqueda y uso de información?". A esto contestaríamos afirmativamente, aunque admitimos que las implicaciones son relativamente imprecisas. Para hacer algún progreso y hallar 
mejores respuestas, podemos pedir ayuda a los autores que tienen ideas pertinentes acerca de las habilidades y el comportamiento humano. Aquí vamos a hacer uso de las ideas de dos distinguidos y respetados divulgadores académicos: Daniel Kahneman (ganador de un Premio Nobel y profesor emérito de la Princeton University) y Mihaly Csikszentmihalyi (anteriormente en la University of Chicago y ahora en la Claremont Graduate University). Ambos ofrecen enfoques que explican la optimización de la eficacia humana mediante el reconocimiento de la dualidad del cerebro.

\section{Es evidente la utilidad de los enfoques relacionados con la neurociencia para proyectos de investigación en ciencias de información}

Antes de atender a lo que nos dice Kahneman, es importante tener en cuenta que hay una distinción entre las funciones de los hemisferios izquierdo y derecho del cerebro, aclarada primero a partir del estudio de pacientes con daños en un hemisferio, y posteriormente apoyada por neuroimágenes. Hasta la década de 1990 se tenía la sensación de que el hemisferio izquierdo del cerebro era mucho más importante que el derecho, a causa de la fuerte evidencia de que es el lugar importante de las actividades racionales y relacionadas con el lenguaje. En cierto sentido, esto casi hizo desestimar el hemisferio derecho como un área necesaria pero "inferior", donde se llevan a cabo los procesos automáticos animales. Sin embargo, los estudios de pacientes con daño cerebral derecho mostraron que habían perdido importantes áreas de conocimiento, como la interpretación de imágenes y mapas, el uso de metáforas, comprensión de chistes y de los vínculos entre las ideas, y capacidad de entender los problemas de manera integral. Parece que es el lado derecho del cerebro el que responde a preguntas y problemas "a partir de la nada". Lehrer (2012) lo asocia con la creatividad humana. El hemisferio izquierdo produce respuestas más lentamente, trabajando duro para buscar en la memoria, probar ideas y razonar soluciones, pero a menudo parece cansarse y experimenta dificultades para progresar. El hemisferio derecho recoge entonces la información, la experiencia y las ideas generadas por el lado izquierdo y busca respuestas mediante procesos asociativos. Es más, la aparición de una respuesta suele estar marcada por una mayor evidencia de actividad eléctrica en la circunvolución temporal superior anterior, que se encuentra en el hemisferio derecho.

Lo que hace Kahneman (2011) es dar un ligero giro a lo que acabamos de describir. Él habla de Sistema uno (hemisferio derecho), que piensa rápido, es intuitivo, asociativo, metafórico, automático, impresionista y no puede ser "apagado". Y de Sistema dos (hemisferio izquierdo), que en contraste piensa lento, delibera y trabaja duro. En la resolución de problemas participa cuando las cosas se ponen difíciles. Este es el ser consciente; el yo que parece definirnos como individuos. Kahneman señala que la mayor parte del Sistema dos difiere del Sistema uno por su eficacia. El problema, tal como él lo ve, es que el Sistema uno no es bueno con los detalles y se apresura a sacar conclusiones de una manera que podría resultar insuficiente, ya que puede ser irracional, sesgada, y propensa a interferencias. En consecuencia:

"Tal como navegamos en nuestras vidas, normalmente nos dejamos guiar por las impresiones y los sentimientos, y la confianza que tenemos en nuestras intuiciones, creencias y preferencias suele ser justificada. Pero no siempre" (Kahneman, 2011, p. 4).

Argumenta que el Sistema uno puede ser un problema, ya que es propenso a errores debidos a una confianza fuera de lugar y se necesita el Sistema dos, que introduce escepticismo, para gestionar problemas complejos y difíciles. La principal preocupación de Kahneman podría decirse que es el estímulo del pensamiento crítico y de soluciones bien razonadas mediante un uso eficaz del Sistema dos. Esto implica que lo que necesitamos en la vida y en nuestra interacción con la información, es una confianza óptima entre los pensamientos rápido y lento; una cooperación entre los hemisferios derecho e izquierdo; un equilibrio entre el Sistema uno y el Sistema dos.

\section{En el cerebro suceden demasiadas co-} sas para que la mente consciente pueda gestionar los datos y cálculos requeridos incluso por un proceso simple

Donde podríamos encontrar indicios interesantes hacia este equilibrio está en la idea de "flujo". Este concepto elaborado por Csikszentmihalyi (1990) describe un estado mental de inmersión total en una actividad mental o física en la medida en que hay una pérdida de la auto-conciencia y las emociones se dirigen hacia una plena participación en la ejecución y el aprendizaje. Se pueden identificar algunos elementos de este enfoque en las técnicas de meditación orientales, en los sistemas educativos como el Método Montessori, y en el entrenamiento avanzado de deportistas. Tal como lo describe Csikszentmihalyi, es la armonización ideal del Sistema uno y el Sistema dos de Kahneman, en aras de una actividad eficaz, y en última instancia satisfactoria. En un estado de flujo la conciencia aprovecha nuestra intuitiva recepción de
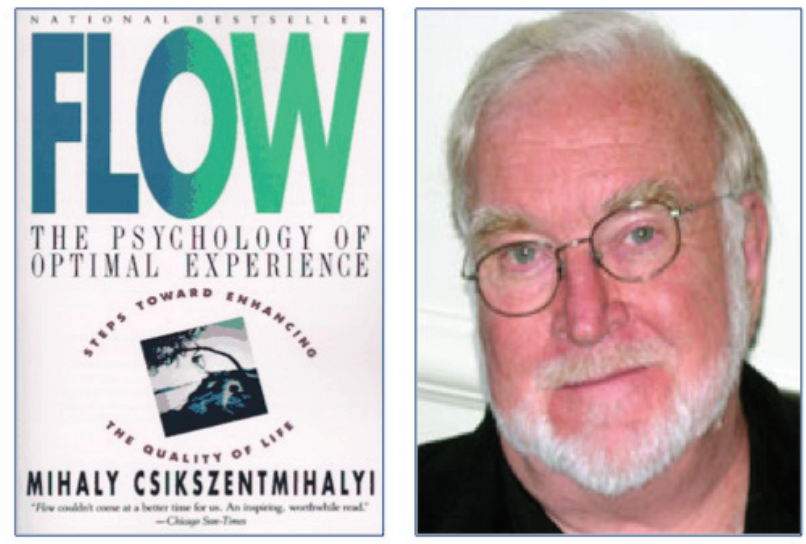

Fuente: http://thepositivelife.info 
la información de una manera decidida.

“La función de la conciencia es representar información acerca de lo que está pasando fuera y dentro del organismo de una manera tal que puede ser evaluada y, si procede, actuar sobre el cuerpo. En este sentido, funciona como centro de intercambio de sensaciones, percepciones, sentimientos e ideas, estableciendo prioridades entre las diversas informaciones. Sin conciencia seguiríamos 'conociendo' lo que está pasando, pero reaccionaríamos de una forma instintiva. Con la conciencia podemos sopesar deliberadamente lo que los sentidos nos dicen y responder en consecuencia" (Csikszentmihalyi, 1990, p. 24).

En situación de flujo el cerebro utiliza ambos sistemas en un equilibrio apropiado a cada ocasión y necesidad. En deportes, por ejemplo, podemos hablar de la zona como un perfecto equilibrio entre la intención consciente y un complejo conjunto de percepciones y cálculos subconscientes. Por ejemplo, la pelota que le llega a un fielder en cricket o en béisbol tiene una velocidad y una trayectoria curva que el ojo no tiene el tiempo de formular como un único mensaje coherente y enviar a las áreas receptoras, y la pelota tiene una dureza y un peso de forma que las manos deben estar perfectamente situadas para recibirla y para que se quede en ellas. Nunca sería recogida correctamente si el cerebro tuviera que hacer un cálculo consciente.

Alfin busca empoderar a la persona que busca información, y para esto el primer paso es entender las fortalezas y debilidades de los procesos mentales individuales

Si tratamos de convertir esto a situaciones de uso de la información de la vida real, el estado de flujo se puede identificar con la naturaleza intuitiva de búsqueda y navegación por la Web. La Web y sus recursos hiperenlazados son particularmente propicios para la experiencia de flujo debido a que el cerebro humano (el hemisferio derecho, en particular) se adapta especialmente a la exploración de los recursos y la búsqueda de oportunidades que tienen estructuras asociadas. Las decisiones basadas en una planificación sistemática previa son menos importantes que las que se toman incidentalmente sobre la marcha en el curso de la exploración y la lectura de los contenidos hipervinculados.

Es cierto que uno puede experimentar más o menos este fenómeno en una gran biblioteca, que en principio se adapta esencialmente a un enfoque racional, de hemisferio izquierdo. Al final de un día recolectando información para una investigación uno se ve rodeado por un montón de libros sacados de los estantes en respuesta a pistas y orientación bibliográfica obtenidas a lo largo del camino. El resultado bien puede ser una aclaración exhaustiva sobre algún tema. Este es, sin embargo, un proceso tortuoso, aunque pueda ser divertido, que requiere el uso del catálogo, conversaciones con los bibliotecarios, idas y venidas a lo largo de las estanterías, consulta de los índices de los libros y otras actividades que requieren mucho tiempo. Esto es flujo, pero no como lo tene- mos que experimentar en la actualidad. El cerebro puede manejar estas conexiones, pistas y punteros de manera mucho más rápida que una biblioteca puede ofrecer los recursos.

Es como si hubiéramos estado esperando algo que pudiera responder a nuestra capacidad inherente para trabajar en flujo. Hoy la espera ha terminado: tenemos una respuesta en la Web, o al menos la mejor respuesta disponible en este momento. Quizá no nos puede decir todo lo que necesitamos conocer y quizá nos proporcione información deficiente o engañosa. Pero permite que nuestra conciencia ponga en juego lo que es claramente nuestro modo de recopilación de información por defecto, que es intuitivo, hemisferio derecho, y definitivamente, Sistema uno.

Así que, para resumir, en un momento dado en el cerebro suceden demasiadas cosas para que la mente consciente pueda gestionar los datos y cálculos requeridos incluso por un proceso simple como ponerse de pie y caminar durante unos pocos pasos. La mayor parte de lo que hacemos (y pensamos) se maneja en algún lugar por debajo del nivel de conciencia. Una vez que reconocemos esto en relación con el uso educativo, profesional y de ocio de la información, podemos ver que es casi inconcebible una actividad de información que proporcione una línea directa garantizada entre la necesidad de conocer (aprehendida o implícita) y alguna forma de resolución de la necesidad.

Una única línea de investigación o un documento con una respuesta, no es lo que necesitamos para trabajar; e incluso puede inhibir el poder de nuestro cerebro de trabajar más productivamente. Necesitamos la exposición de una información amplia, del tipo de la que podríamos encontrar en una biblioteca muy grande y muy accesible, y de la que ahora tenemos un equivalente virtual a nuestra disposición en la Web tanto a través de dispositivos fijos como móviles. Podemos sumergirnos (explorar o navegar) con toda naturalidad, lograr el flujo, experimentar serendipidad, dejar que nuestra imaginación vuele libremente y llegar a conclusiones inesperadas. En esencia lo que estamos haciendo implícitamente es aceptar el mensaje que aprendemos de la neurociencia. Esto es lo que necesitamos para liberarnos de una excesiva preocupación inútil con la mente consciente y poner los dos hemisferios del cerebro en el centro de nuestro universo de la información.

\section{Conclusión}

Este intento de aprender algo de la neurociencia que sea relevante para las ciencias de la información, se ha hecho para proponer un enfoque a la ciencia de la información centrado en el cerebro. Ciertamente pensamos que es evidente la utilidad de los enfoques relacionados con la neurociencia para proyectos de investigación en ciencias de información. Por poner sólo un ejemplo, son considerables las implicaciones para la alfabetización informacional (alfin).

Anteriormente hemos sugerido que en nuestra relación con la información tenemos que aceptar la importancia de la rápida actividad mental de nuestro hemisferio derecho, Sistema uno. Pero necesitamos incorporar un hábil sistema de discriminación en el Sistema dos. La búsqueda Sistema uno es emocionante y productiva, pero lleva implícita el peligro 
de incorporar un cierto grado de error, sesgo o confusión. Esto requiere un contrapeso. Los programas de alfin buscan empoderar a la persona que busca información, y para esto el primer paso es entender las fortalezas y debilidades de los procesos mentales individuales. Una vez establecidos los puntos fuertes y débiles, se podrá diseñar la selección de los contenidos para los alumnos que asisten de manera más efectiva y adecuada. No es difícil imaginar formas en las que científicos de la información y neurocientíficos en colaboración puedan idear un programa de investigación que arroje luz sobre este tema y otros en ciencias de la información.

\section{Referencias}

Appleyard, Bryan (2011). The brain is wider than the sky: why simple solutions don't work in a complex world. London: Weidenfeld and Nicolson. ISBN: 9780297860303

Carr, Nicholas (2010). The shallows: how the Internet is changing the way we think, read and remember. London: Atlantic Books. ISBN: 9781848878839

Churchland, Patricia S. (2013). Touching a nerve: the self as brain. New York: W. W. Norton. ISBN: 9780393058321

Csikszentmihaly, Mihaly (1990). Flow: the psychology of optimal expression. New York: Haper and Row. ISBN: 978 0060162535

Eagleman, David (2011). Incognito: the secret lives of the brain. Edinburgh: Canongate. ISBN: 9780307377333

Edelman, Gerald M. (2006). Second nature: brain science and human knowledge. New Haven: Yale University Press. ISBN: 9780300120394

Floridi, Luciano (2010). Information: a very short introduction. Oxford: University Press. ISBN: 9780199551378

Gay, Volney P. (2009) (Ed.) Neuroscience and religion: brain, mind, self and soul. Lanham MA: Lexington Books. ISBN: 978 0739133927

Gleick, James (2011). The information: a history, a theory, a flood. London: Fourth Estate. ISBN: 9780375423727

Goldblum, Naomi (2001). The brain-shaped mind: what the brain can tell us about the mind. Cambridge: University Press. ISBN: 9780521000949

Hick, John (2006). The new frontier of religion and science: religious experience, neuroscience and the transcendent. Basingstoke: Palgrave Macmillan. ISBN: 9780230507708

Hood, Bruce M. (2009). Supersense: from superstition to religion - the brain science of belief. London: Constable. ISBN: 9781849010306

Kahneman, Daniel (2011). Thinking, fast and slow. London:
Allen Lane. ISBN: 9780374275631

Kaku, Michio (2014). The future of the mind: the scientific quest to understand, enhance and empower the mind. New York: Doubleday. ISBN: 9780385530828

Kwint, Marius; Wingate, Richard (2012). Brains: the mind as matter. London: Wellcome Collection. ISBN: 978 1781250402

Ledoux, Joseph (2002). Synaptic self: how our brains became who we are. London: Penguin. ISBN: 9780142001783

Lehrer, Jonah (2012). Imagine: How creativity works. Edinburgh: Canongate. ISBN: 9780547386072

Ramachandran, Vilaynur S. (2004). A brief tour of human consciousness: from impostor poodles to purple numbers. New York: Pi Press. ISBN: 9780131486867

Ramachandran, Vilaynur S.; Blakeslee, Sandra (1999). Phantoms in the brain: human nature and the architecture of the mind. London: Fourth Estate. ISBN: 9781857028959

Rose, Steven (2006). The twenty-first century brain: explaining, mending and manipulating the mind. London: Vintage. ISBN: 9780099429777

Satel, Sally; Lilienfeld, Scott O. (2013). Brainwashed: the seductive appeal of mindless neuroscience. New York: Basic Books. ISBN: 9780465018772

Scholl, Jeffrey D. (2009). "Actions, reasons, neurons and causes". In: Gay, V. (ed.). Neuroscience and religion: brain, mind, self and soul. Lanham MA: Lexington Books. pp. 175198. ISBN: 9780739133927

Seung, Sebastian (2012). Connectome: how the brain's wiring makes us who we are. Boston MA: Houghton Mifflin Harcourt. ISBN: 9780547508184

Shannon, Claude E.; Weaver, Warren (1949). The mathematical theory of communication. Urbana IL: University of Illinois Press.

Tallis, Raymond (2011). Aping mankind: neuromania, darwinitis and the misrepresentation of humanity. Durham: Acumen. ISBN: 9781844652723

Wilson, Thomas D. (2000). "Human information behaviour". Informing science, v. 3, n. 2, pp. 49-56.

http://inform.nu/Articles/Vol3/v3n2p49-56.pdf

Winston, Robert (2003). The human mind and how to make the most of it. London: Bantam Books. ISBN: 978 0593052105

Zimmer, Carl (2005). Soul made flesh: the discovery of the brain and how it changed the world. London: Arrow Books. ISBN: 9780743272056 